\title{
SEXUAL DYSFUNCTION AFTER SPINAL CORD OR CAUDA EQUINA LESIONS
}

\author{
By Eilif Larsen and Niels HejgaARd \\ Senior Registrars, Specialists in Orthopaedic Surgery, Department of Neurosurgery, \\ Glostrup, University of Copenhagen.
}

Summary. In the neurological follow-up 68 patients with a history of spinal cord or cauda lesions of different aetiology and in different stages of regression were examined and interviewed concerning pre- and postmorbid sexual function.

As to sexual dysfunction there was no difference between men and women. There was little relationship between the patients' motor function and their present sexual activity. On the other hand there was a statistically significant relationship between bladder dysfunction and sexual dysfunction.

In elderly patients sexual activity was often reduced and also in cases of complete neurological restitution.

Stability of the patients' marriage was as in the population on the whole.

It is concluded that not only young patients, but also elderly ones, had a need for sexual rehabilitation after treatment for spinal cord or cauda equina lesion.

Key words: Spinal cord lesions; Cauda equina lesions; Sexual dysfunction.

\section{Introduction}

MANY somatic diseases may cause sexual dysfunction and during the past decades this has been discussed with increasing frequency (Baldursson and Brattström, I979; Bors and Comarr, I960; Comarr, I962).

According to Jackson (1972), patients with spinal cord lesions often show a discrepancy between practical sexual ability and neurological status.

Bors and Comarr (1960), Griffith et al. (I973), Tarabulcy (I972), Vinken and Bruyn (I976) and Wahle and Jochheim (I970) have given detailed descriptions of the nervous disturbances and causes of sexual dysfunction in para- and tetraplegics. But there is a lack of study elucidating changes and restitution of sexual function in patients with a history of spinal compression syndromes of different aetiology. Few authors have investigated the sexual function of women and elderly patients in this category, Bors and Comarr (1960), Nielsen et al. (1979).

The object of the present retrospective study was to assess actual sexual experience in patients with or without sequelae to cord and cauda equina compression syndromes or traumatic lesion of the cord. Furthermore to ascertain these patients wishes and potentials for establishing sexual contacts.

\section{Patients and Methods}

During the period January I975 to January I980 a total of I49 patients

Send reprint request to Eilif Larsen, Lyngvigvej I4, DK-2720 Vanløse, Denmark. 
were admitted with clinical symptoms and signs of cord or cauda equina compression or traumatic lesion of the cord to the Department of Neurosurgery, University Hospital, Glostrup, Copenhagen.

At the time of follow-up 79 had died and two had emigrated. The remaining 68 patients had a neurological examination and were interviewed concerning their sexual function, premorbid and present. For ethical reasons the interview was carried out in privacy by one of the authors.

The extent of neurological deficit was graded by the Frankel et al (1969) classification (Table I).

The neurological classification was based upon the status at follow-up.

TABLE I

Neurological regression correlated to the classification of Frankel et al.

\begin{tabular}{|c|c|c|c|c|c|c|}
\hline \multirow{2}{*}{\multicolumn{2}{|c|}{$\begin{array}{l}\text { Neurological group } \\
\text { at admission }\end{array}$}} & \multicolumn{5}{|c|}{ Neurological group at follow-up } \\
\hline & & A & B & $\mathrm{C}$ & & $\mathbf{E}$ \\
\hline A & 13 & 5 & I & 2 & 3 & 2 \\
\hline B & 9 & I & I & I & 4 & 2 \\
\hline C & 23 & & & 2 & I I & IO \\
\hline D & 20 & & & I & 9 & IO \\
\hline $\mathrm{E}$ & 3 & & & & I & 2 \\
\hline To & 68 & 6 & 2 & 6 & 28 & 26 \\
\hline
\end{tabular}

A: 'Complete'. This means that the lesion was complete, both motor and sensory, below the affected segment.

B: 'Sensory only'. This implies some sensation below the level of the lesion, but complete motor paralysis below that level.

C: 'Motor useless'. This implies some motor power below the lesion, but of no practical use to the patient.

D: 'Motor useful'. This implies useful motor power below the level of the lesion. The patient could move the limbs and many could walk, with or without aids.

E: 'Recovery'. This implies that the patient was free of neurological symptoms. Abnormal reflexes may have been present.

TABLE II

Sexological definitions

Men

Erective dysfunction: No erective reaction on erotic stimulation.

Ejaculatio praecox: $\quad$ Ejaculation too soon in the sexual act.

Ejaculato retarda: Delayed or lacking ejaculation.

Reduced libido: $\quad$ A reduced desire for sexual activity in relation to the person's wishes and expectations.

Women

Excitational dysfunction Reduced vaginal lubrication on stimulation.

Orgastic dysfunction: Lacking ability to obtain orgasm during sexual intercourse or masturbation.

Vaginism: Vaginal spasm (not present in any of the patients examined).

Reduced libido: $\quad$ A reduced desire for sexual activity in relation to the person's wishes and expectations. 
TABLE III

Causes of neurological deficit, number of patients, age and sex ratio

\begin{tabular}{|c|c|c|c|c|}
\hline$\overline{\text { Aetiology }}$ & No. of pt.'s & $\begin{array}{c}\text { Age in years } \\
\text { (mean and range) }\end{array}$ & Women & Men \\
\hline Tumour without $<$ malignant & I & 49 & I & \\
\hline bony involvement benign & 31 & $49(\mathrm{I} 7-8 \mathrm{I})$ & I5 & I 6 \\
\hline Tumour with $<$ malignant & 6 & $54(43-6 I)$ & 3 & 3 \\
\hline bony involvement benign & II & $58(45-73)$ & 5 & 6 \\
\hline Trauma & 19 & $30(14-67)$ & 3 & I6 \\
\hline Total & 68 & $46(\mathrm{I} 4-8 \mathrm{I})$ & 27 & 4I \\
\hline
\end{tabular}

TABLE IV

Level of lesion in the neurological groups at follow-up

\begin{tabular}{lcccccc}
\hline \multicolumn{1}{c}{ Lesion level } & \multicolumn{9}{c}{ Neurological groups } & & Total \\
(both complete and incomplete) & A & B & C & D & E & \\
\hline Cervical & 5 & I & 3 & 9 & 6 & 24 \\
Thoracic TI-T9 & I & I & I & 9 & 6 & I8 \\
Thoracolumbar TIO and below & 0 & 0 & 2 & IO & I4 & $26^{\star}$ \\
\hline Total & 6 & 2 & 6 & 28 & 26 & 68 \\
\hline
\end{tabular}

*Cauda equina syndromes in eleven patients.

In evaluating sexual dysfunction we used the criteria of Jensen (I978) and Nielsen et al. (1979), Table II.

Loss of control of micturition as well as urinary retention were interpreted as disturbance of bladder function as well as cases of a functioning manual compression bladder.

Table III gives the aetiology of the disease as well as the age distribution and sex ratio.

The follow-up period ranged from I to 5.8 years, mean 3.9 years. Table IV gives the level of lesion in the different neurological groups at follow-up. In I 9 patients with traumatic aetiology the predominant site was the cervical spine. Malignant tumours had been demonstrated in seven patients, mostly in the lower thoracic spine, while benign tumours (present in 42 cases), were of equal distribution in the entire spine.

In the non-traumatic group 42 patients had been treated surgically by decompression laminectomy and partial or total removal of the tumour. In the remaining seven cases the treatment had been non-operative because the symptoms and signs were transient (five cases) or a sequel to haematoma (two cases). In the traumatic cases the treatment used was Gardner-Well's skull traction in 12 cases and Stryker's turning frame bed in seven.

As for other diseases one patient of group C, and two each of groups $\mathrm{D}$ and $\mathrm{E}$, were well-controlled on antihypertensive treatment at the time of follow-up. One patient in group D and one in group E had angina pectoris. Other features were sequelae to the basic disease, including bilateral cutaneous ureterostomy in one patient and decubital ulcers on the buttocks in four. 


\section{Results}

The duration until the condition became stationary ranged uniformly in all neurological groups from I to 24 months (mean 9 months). Three patients reported a feeling of improvement in their condition at the time of follow-up.

Sixteen patients (24 per cent) had no sexual life before their disease or at follow-up. Their mean age was 56 years (I4-8I years) and the sex ratio was ten females to six males. Of them five ( 7 per cent) reported a desire for sexual activity but lacked the ability to carry it through. Table $\mathrm{V}$ shows the level of lesion related to sexual dysfunction in the neurological groups. Five out of eleven patients with cauda equina syndromes had sexual dysfunction.

\section{TABLE V}

Level of lesion related to sexual dysfunction in the neurological groups at follow-up

\begin{tabular}{lcccccc}
\hline \multirow{2}{*}{$\begin{array}{l}\text { Lesion level } \\
\text { (both complete and incomplete) }\end{array}$} & \multicolumn{4}{c}{ Sexual dysfunction in } & & Total \\
& A the neurological groups & & \\
\hline Cervical & B & C & D & E & \\
Thoracic TI-T9 & 5 & I & 2 & 2 & 3 & I3 \\
Thoracolumbar TIO and below & I & I & I & 5 & I & 9 \\
Total & 6 & O & I & 7 & 5 & I3 $^{\star}$ \\
\hline
\end{tabular}

ॠCauda equina syndromes in five patients.

Figure I gives the number of patients without any sexual life after the disease, related to aetiology and the Frankel grade. The same figure shows patients having a more or less active sexual life at the time of follow-up.

Figure 2, similarly, presents the frequency of deterioration of sexual function in the various groups.

Figure 3 sets out the reduction in sexual function in relation to age and and to the Frankel classification. There was a non-significant reduction

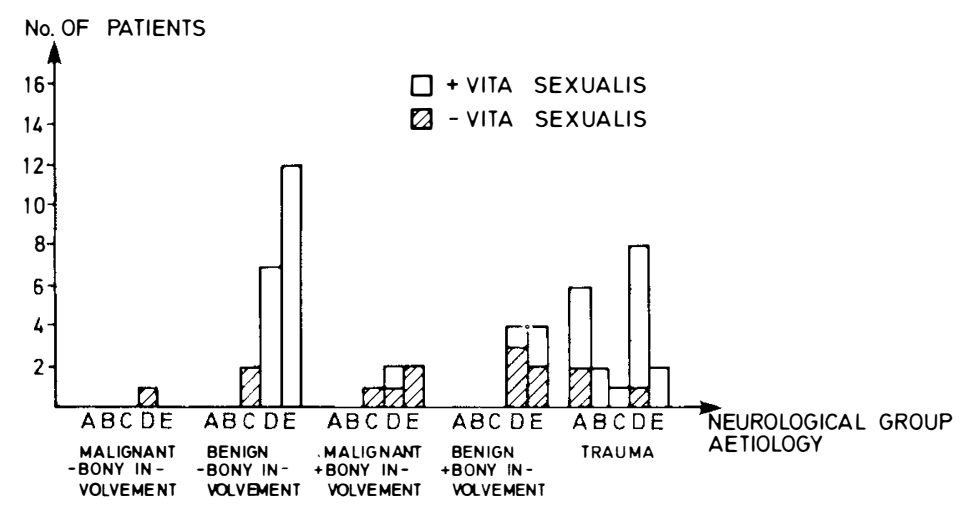

FIG. I

Number of patients with and without any sexual life related to aetiology and Frankel grade. 


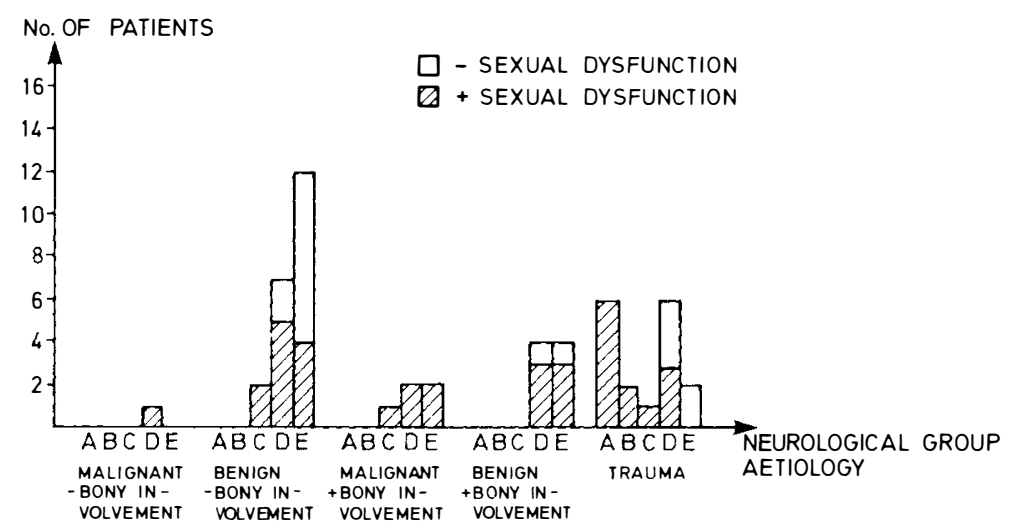

FIG. 2

Sexual dysfunction related to aetiology and Frankel grade.

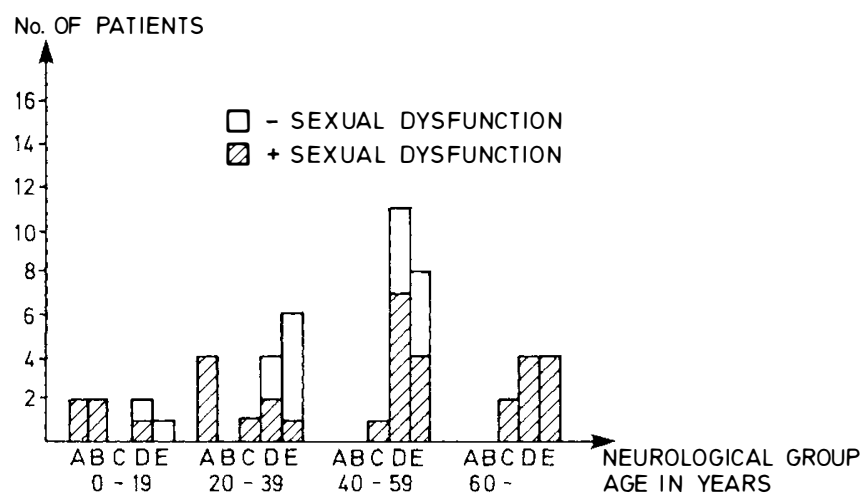

FIG. 3

Sexual dysfunction related to the age and Frankel grade.

in sexual life with advancing age (chi square test, $\mathrm{p}=0.08 \mathrm{I}$ ). There was, however, no sex difference in the whole group (Fischer's exact test, $\mathrm{p}=0.5 \mathrm{I} 6)$.

Comparison of the patients in groups $\mathrm{D}$ and $\mathrm{E}$, without bony involvement, with groups $\mathrm{D}$ and $\mathrm{E}$ having bony involvement revealed more patients with reduced sexual function in the latter. However, the difference was not significant (Fischer's exact test, $\mathrm{p}=0.336$ ).

When the traumatic group is included the findings in groups D and $\mathrm{E}$ are essentially similar to those in patients without bony involvement. However, the most severe cases in groups $\mathrm{A}, \mathrm{B}$ and $\mathrm{C}$ are not comparable with other groups.

Figure 4 illustrates the relationst;ip between bladder function, age and sexual dysfunction. This figure clearly shows a relationship between the reduction in sexual activity and impaired bladder function (Fischer's exact test, $\mathrm{p}=0.0037$ ).

In all the patients with unchanged sexual function despite an impaired 


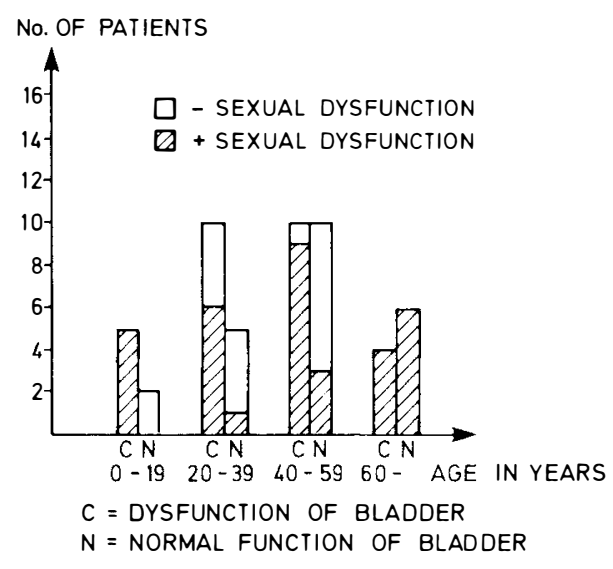

FIG. 4

Relationship between bladder function, age and sexual dysfunction.

bladder function, the bladder disturbance consisted of mild stress incontinence only.

Spasms were demonstrated in all patients of group A and B, in two out of seven in group C, and four of 24 in group D and in three out of 24 in group E. Four patients were greatly inconvenienced by the spasms during intercourse, while on the other hand a young man of group A utilised the spasms to induce ejaculation.

The incidence of pain in the individual groups was as follows:

I. Tumour without bony involvement I I of 3 I patients (35 per cent).

2. Tumour with bony involvement eight of 17 (47 per cent).

3. Trauma, seven of 19 patients (37 per cent).

The position during intercourse was in both sexes supine, with increasing frequency from group $\mathrm{E}$ to group $\mathrm{A}$.

Table VI sets out the causes of sexual dysfunction in the various neurological groups, IOO patients without pre- and postmorbid sexual contacts being included. Several symptoms may be present in the same patient.

\section{TABLE VI}

Sexological dysfunction in the different neurological groups at follow-up. (Included patients without sexual contacts pre- and postmorbid)

\begin{tabular}{lccccccc}
\hline & & \multicolumn{3}{c}{ Neurological groups } & \multicolumn{2}{c}{ Total } \\
& A & B & C & D & E & \\
\hline Erective dysfunction & I & & 2 & 7 & 5 & I5 \\
Ejaculatio praecox & & I & 3 & 5 & 4 & I3 \\
Ejaculatio retarda & 4 & 2 & 2 & 5 & 2 & I 5 \\
Reduced libido & 5 & I & 2 & 7 & 7 & 22 \\
Excitational dysfunction & I & & & 9 & 5 & I5 \\
Orgastic dysfunction & I & & I & 6 & 5 & I3 \\
Vaginism & & & & & & I6 \\
Reduced libido & I & & & 9 & 6 & I6 \\
\hline
\end{tabular}


Two patients of group D were divorced; two engagements in group A and one in group $\mathrm{D}$ had been broken because of the disease. Seven patients, one of group A, two of group B, and four of group D had acquired new partners. No progeny had been produced after the onset of the disease. Eight patients (12 per cent) with a history of a normal sex life before the disease reported that they still had the desire but did not have the ability to establish a sex life.

Two patients of group D and one patient of group E had sought medical advice because of sexual problems.

\section{Discussion}

Partial or total preservation of the sexual potential is partly related to the degree, level and type of the spinal lesion but psychological factors also influence sexual function (Uyttendaele $e t$ al., I979).

However, other factors must be expected to affect the sexual function, e.g. (I) age, (2) sex, (3) associated diseases, (4) medication, (5) acquired sequelae to the disease, (6) partner relations and (7) opportunities for sexual activity.

Not surprisingly most sexual activity was found among the younger patients despite persistent, often serious, neurological deficits. According to Jackson (1972), an important factor is the patient's social education concerning sexual activity; but the possibilities of entering into a permanent partner relationship must be considered to be an additional factor.

Most reduction in, and most often complete cessation of any sexual life, was found among the elderly patients, characteristically most commonly among patients with bony involvement or a malignant basic disease. That reduction in sexual activity cannot be ascribed solely to age is apparent from Jensen et al.'s (1978) as well as Baldursson and Brattström's (I979) studies. Investigating patients with long-standing diabetes and over 55year-old patients with a history of hip replacement respectively, they found an appreciably smaller reduction in sexual activity than we did in the present series. Pain was a fairly outstanding feature in our material and this may supply part of the explanation. The influence of the basic disease in these patients is more difficult to assess because of the relatively small number.

Bladder dysfunction was often accompanied by sexual difficulties in spite of reasonable motor function. This is explicable in part by the presence of perineal hypo-aesthesia or anaesthesia but also by the fear of involuntary urination during intercourse. Contributory causes may be the use of a micturition bag, indwelling catheter or diaper.

It was not possible to demonstrate any difference in sexual dysfunction between men and women. According to Tarabulcy (1972), fertility and ability to conceive are preserved in 80 per cent of the women and ejaculation in IO-25 per cent of the men with para- or tetraplegia; but in our series no patient had been pregnant or had children after the onset of the disease.

Surprisingly, only three patients had been in touch with a sexologist. In present-day Denmark it is customary to give young para- and tetraplegics thorough information concerning the possibilities of help and aids to promote sexual life, while this does not apply often to other groups of patients with less fulminant neurological, somatic or psychological sequelae to spinal compression or cord affecting syndromes. 
Sexual dysfunction, in terms of the criteria stated above, proved to be most marked in patients with serious neurological sequelae but was also common in patients over 60 years of age, although they did not have serious motor or bladder function disturbances. This was unrelated to the aetiology of the disease and must be interpreted to mean that with advancing age somatic diseases affecting the spine exert an increasing influence upon sexual function.

The number of divorces indicates the same stability in the patients' marriage as in the population on the whole. This has been confirmed by Comarr (1962) and Deyve (I972), but Guttmann (1964) reported a higher proportion of divorces among paraplegics and tetraplegics.

\section{Conclusion}

In elderly patients sexual activity was often reduced and also in cases of complete neurological restitution.

According to the results, not only young patients but also elderly ones, had a need for sexual rehabilitation after treatment for spinal syndromes.

Regardless of the cause of the lesion these patients remain sexual beings, especially the younger, but also the older age groups.

\section{RÉSUMÉ}

Dans une étude ultérieure neurologique 68 souffrants qui avaient une histoire de lésions de la moelle épinière ou de la queue, d'une étiologie différente et à des degrés différents de régression, ont ete examinés et interviewés au sujet de la fonction sexuelle tant prémorbide que postmorbide.

Quant au dysfonctionnement sexuel il n'y avait aucune différence entre les hommes et les femmes. Il y avait peu de rapport entre la fonction motrice des souffrants et leur activité sexuelle actuelle. D'autre part il y avait un rapport statistiquement significatif entre le dysfonctionnement de la vessie et le dysfonctionnement sexuel.

Chez les souffrants âges l'activité sexuelle se trouvait souvent réduite, comme dans les cas de restitution neurologique complète aussi.

La stabilité du mariage des souffrants était comme chez la population en général.

On arrive à la conclusion que non seulement les jeunes souffrants, mais aussi les âgés avaient besoin de la réhabilitation sexuelle après le traitement pour une lésion de la moelle épinière ou de la queue de cheval.

\section{ZUSAMMENFASSUNG}

In einer neurologischen Nachbeobachtung sind 68 Pazienten mit einer Geschichte von Rückenmark- oder Schwanzverletungen von verschiedener Ätiologie und mit verschiedenen Stufen von Rückfall über die Vorkrankheit- und die Nachkrankheitsgeschlechtsfunktion untersucht und interviewt worden.

Was die geschlechtliche Dysfunktion betrifft, gab es keinen Unterschied zwischen Männern und Frauen. Es gab wenig Beziehung zwischen der Motorfunktion der Pazienten und ihrer aktuellen geschlechtlichen Tätigkeit. Andererseits gab es eine statistisch bedeutsame Beziehung zwischen Blasendysfunktion und geschlechtlicher Dysfunktion.

Bei älteren Pazienten wurde die geschlechtliche Tätigkeit oft vermindert, wie auch in Fällen von völliger neurologischer Wiederherstellung.

Die Standhaftigkeit der Ehe der Pazienten war so, wie bei der Bevölkerung insgesamt.

Man beschliesst zwar, dass nicht nur die jungen Pazienten, sondern auch die älteren, einen Bedarf nach geschlechtlicher Rehabilitierung nach der Behandlung für Rückenmarkoder Pferdeschwanz-Verletzung hatten. 


\section{REFERENCES}

Baldursson, H. \& Brattström, H. (1979). Sexual difficulties and replacement in rheumatoid arthritis. Scand. F. Rheumatol., 8, 214-216.

Bors, E. \& ComArR, E. (I960). Neurological disturbances of sexual function with special references to 529 patients with spinal cord injuries. Urol. Survey, Io, I9I-22I.

Comarr, A. E. (I962). Proc. I Ith Ann Clin. Spinal cord conference. Veteran Administration Hosp., Bronx, New York. 209-2 I I.

Deyve, F. S. (1972). Marriage and family patterns with long-term spinal cord injury. Paraplegia, 10, 2 I.

Frankel, H. L., Hancock, D. O., Melzak, J., Michaelis, L. S., Ungar, G. H., Vernon, J. D. S. \& WALSH, J. J. (1969). The value of postural reduction in the initial management of closed injuries of the spine with paraplegia and tetraplegia. Paraplegia, 7, 179-192.

Griffith, E. R., Tomko, M. A. \& Timms, R. J. (1973). Sexual function in spinal cordinjured patients: A review. Arch. Phys. Med. Rehabil., 54, 539-543.

Guttmann, L. (1964). The married life of paraplegics and tetraplegics. Paraplegia, 2, 182.

Jackson, R. W. (1972). Sexual rehabilitation after cord injury. Paraplegia, 10, 50-55.

Jensen, S. B. (1978). Sexual dysfunction and somatic diseases in men. Ugeskr. Lag., 140, 2095-2 102. English Summary.

Jensen, S. B., Hagen, C. \& Frøland, A. (1978). Sexual dysfunction in diabetic men. Ugeskr. Lag., 140, 2 102-2 105. English Summary.

Nielsen, I. L., Garde, K., Fog, E., Larsen, G. K. \& Nielsen, D. F. (I979). Sexology and epidemiological methods. A pilot investigation of women's sexual behaviour, experience, knowledge and attitudes. Ugeskr. Lag., I4I, I93 I-I 935. English Summary.

Tarabulcy, E. (1972). Sexual function in the normal and in paraplegia. Paraplegia, oo, $20 \mathrm{I}-208$.

Uyttendaele, D., D'Hoogde, M., Brusselmans, W. De Grote, W. \& Claessens, H. (1979). The sexual problem in the tetra- and paraplegia. Acta Orthop. Belg., 45, 470-479.

Vinken, P. J. \& BRUYN, G. W. (1976). Injuries of the spine and spinal cord. American Elsevier Publishing Co., Inc., New York, 437-46I.

WAHLE, H. \& JochHEIM, K. A. (I970). Untersuchungen über neurogene störungen der Sexualfunktion bei 56 querschnittgelähmten Männern mit kompletten irreversiblen Scädigungen des Rückenmarks oder der Cauda Equina. Fortschr. Neurol. Psychiat., 38, I92-20I. 